\title{
Knowledge and Attitudes Among Medical Students
}

\section{Toward the Clinical Usage of e-Cigarettes: A}

\section{Cross-Sectional Study in a University Hospital in Saudi Arabia}

\author{
Sami H Alzahrani $\mathbb{D}^{\prime}$ \\ Rawan A Alghamdi ${ }^{2}$ \\ Ahmed Mabruk Almutairi (iD) ${ }^{3}$ \\ Ali Ahmed Alghamdi $\left(\mathbb{D}^{3}{ }^{3}\right.$ \\ Abdullah Abdulwahab \\ Aljuhani $\mathbb{D}^{3}$ \\ Abdulrahman Hamed \\ ALbalawi $\mathbb{D D}^{3}$ \\ 'Family Medicine Department, Faculty of \\ Medicine, King Abdulaziz University, \\ Jeddah, Saudi Arabia; ${ }^{2}$ Ibn Sina National \\ College for Medical Studies, Jeddah, Saudi \\ Arabia; ${ }^{3}$ Faculty of Medicine, King \\ Abdulaziz University, Jeddah, Saudi Arabia
}

Correspondence: Sami H Alzahrani Family Medicine Department, Faculty of Medicine, King Abdulaziz University, PO Box 80205, Jeddah, 21589, Saudi Arabia Tel +9669500004062

Email drsamihz@gmail.com
Background: To assess knowledge and attitudes about e-smoking among undergraduate medical students, specifically focused on favorable view of therapeutic e-cigarette use for smoking cessation or harm reduction.

Methods: This cross-sectional study included medical students at King Abdulaziz University, Saudi Arabia. A six-item subscale was used to explore knowledge and attitudes about the therapeutic use of e-cigarettes, measuring participants' likelihood of favoring such use. A four-item questionnaire measured confidence and importance of being educated about smoking and e-smoking, in addition to sources of knowledge about e-cigarettes.

Results: A total of 399 students participated. Smoking history included current smokers $(19.8 \%)$ and ex-smokers (6.5\%), while e-cigarettes were tried by $36.6 \%$ and are currently used by $11.5 \%$. A minority (13.5\%) believed that e-cigarettes are FDA-approved for smoking cessation, while approximately one-third believed e-smoking lowers cancer risks $(31.1 \%)$ and could help with smoking cessation (31.1\%). Further, 35.9\% agreed or strongly agreed that e-cigarettes are better for patients than tobacco products, and $17.5 \%$ were likely to recommend e-smoking to their patients for smoking cessation. Reliability of the six-item scale showed Cronbach's alpha $=0.676$, which was enhanced to 0.746 after deletion of one item about addictiveness. Using the corrected five-item scale, $23.6 \%$ of the participants would favor therapeutic use of e-cigarettes.

Conclusion: We observed several misconceptions about addictiveness and inadequate awareness about e-cigarettes' harmful effects, leading to non-scientific opinions about its therapeutic use for harm reduction or in smoking cessation. Academic programs around this topic should be updated in accordance with majority expert recommendations.

Keywords: e-cigarette, vaping, knowledge, therapeutic, smoking cessation, medical students, Saudi Arabia

\section{Background}

Cigarette smoking was common globally starting in the 1900s. Smoking rates increased in exponential increments, which was associated with significant morbidities and mortalities in high- and middle-income countries. ${ }^{1}$ Approximately 8 million deaths are reported annually from tobacco smoking; additionally, total economic costs attributable to smoking-related productivity losses and health care expenditures are substantial. ${ }^{2}$ However, recent estimates show that the global rates 
of smoking among individuals aged $>15$ years declined from $23.5 \%$ to $20.7 \%$ between 2007 and $2015,{ }^{3}$ possibly due to the establishment of effective anti-smoking efforts and laws.

Concurrently, the use of electronic cigarettes (E-cigarettes) has increased, particularly among youth and young adults. E-cigarettes comprise a heating device powered by a battery that delivers nicotine to the mouth and upper airways. The heating device contains a fluid mixture of vegetable glycerin, propylene glycol, and flavors other than nicotine. It is activated manually or by suction, transforming a nicotine solution into a vaporized form. ${ }^{4}$ The use of e-cigarettes continues to increase since they are marketed as healthier alternatives to tobacco smoking.

For instance, data from the Georgia State University Tobacco Products and Risk Perceptions Survey ${ }^{5}$ indicated that the prevalence of e-cigarette use between 2015 and 2018 increased significantly among those who never smoked before and former smokers, from $3 \%$ to $5 \%$ and from $5.3 \%$ to $12.9 \%$, respectively. These trends were apparent among young adults aged 18-24 who have used emerging popular products such as water pipes and e-cigarettes. ${ }^{6}$ In Saudi Arabia, the results of a large online survey revealed that $33.5 \%$ had previously tried e-cigarettes, and $7.5 \%$ of those were current users. ${ }^{7}$ The prevalence among current tobacco smokers is even higher, where $68.9 \%$ of them are active e-cigarette users, either daily or occasionally. ${ }^{8}$

These attitudes are alarming, especially with the significant gaps in knowledge regarding the benefits and risks of e-cigarette use. Although e-cigarettes may help current smokers quit their harmful habit, ${ }^{9}$ little is known about the potential harm from e-cigarettes, especially over a long period. Such conflicts may also extend to the potential safety concerns in distinct populations, including young adults and pregnant women. Importantly, the Centers for Disease Control and Prevention (CDC) underscored the increased risk of tobacco use among nonsmokers, delayed smoking cessation among current tobacco smokers, and increased exposure to nicotine poisoning and secondhand smoke among young adult e-cigarette users. ${ }^{10}$ These consequences show that in this age category, e-cigarettes can be a gateway to tobacco smoking. Given the rising trend of e-cigarette use among teenagers and youths, as well as the lack of high-quality studies that have investigated their safety, it is imperative to increase awareness levels and reinforce education regarding e-cigarette use. This could be carried out earlier among school and university students.

More specifically, medical students represent a significant target, since they are future health professionals who will bear their responsibility of providing adequate knowledge and promoting healthy habits among their patients. It is therefore necessary to assess their perceptions, awareness, and knowledge about smoking habits, including the use of e-cigarettes. Subsequently, the attitudes and perceptions of the general population will be formed, and this will affect future smoking cessation strategies. In Saudi Arabia, little is known about the awareness and knowledge of medical students, which hinders future efforts targeting the health of the general public through effective smoking cessation strategies. The present study aimed to assess the knowledge and attitudes of medical students regarding e-smoking, with a specific focus on their tendency to favor the therapeutic use of e-cigarettes as a smoking cessation method.

\section{Methods}

\section{Population and Setting}

This cross-sectional study was carried out among undergraduate medical students at King Abdulaziz University (KAU) Faculty of Medicine, Jeddah, Saudi Arabia, in the period May through June 2020. It included medical students in their second through sixth years, who were aged 18 to 30 , while it excluded students from other colleges such as pharmacology or dentistry. The study protocol and questionnaire were reviewed and ethically approved by the Institutional Review Board of KAU (IRB No 20602), and the study procedures were carried out in concordance with the Declaration of Helsinki.

\section{Sampling}

Considering there is an unknown percentage of participants who would be in favor of clinical usage of e-smoking, the sample size was calculated from the total population of 2410 medical students, with a 5\% margin of error and $95 \%$ confidence interval. The target sample size was determined to be 332 and was increased to $400(N$ $=400)$ to compensate for eventual incomplete participations.

The target population was stratified by academic level (second, third, etc. year) and a proportional allocation was used to randomly include participants for the following proportions: $25 \%$ of the sample from the second year, $20 \%$ 
from the third year, $21 \%$ from the fourth year, $17 \%$ from the fifth year, and $15 \%$ from the sixth year.

\section{Instrument}

A semi-structured questionnaire containing four parts was designed by the authors. Part one collected sociodemographic and academic data, including age, gender, marital status, place of residence, academic year, and grade point average (GPA). Part 2 collected clinical data and exposure to smoking and e-smoking, including body mass index (BMI), chronic diseases (asthma, hypertension, diabetes, etc.), smoking status, experience with e-smoking, and current use of e-cigarettes. Part 3 explored knowledge and attitudes regarding the clinical use of e-cigarettes and e-smoking, including items such as whether they are approved by the US Food and Drug Administration (FDA) for smoking cessation, whether they lower the risk of cancer as compared to tobacco products, and whether the student would recommend e-smoking to patients as a smoking cessation method or harm reduction approach. Part 4 comprised four items measuring confidence in and importance of being educated about smoking and e-smoking counseling, in addition to sources of knowledge about e-cigarettes (such as social media, online advertising, and so on). A full list of the questionnaire items and domains is presented in Table S1.

\section{Validation and Scoring System}

The face and content validity of the questionnaire was evaluated and confirmed by two independent family medicine consultants. The Part 3 subscale was used to measure participants' willingness or lack thereof to use e-cigarettes as a smoking cessation method. Depending on the item, answers to the Part 3 subscale were either "yes," "not sure," or "no" for items 1 through 4, or "strongly agree," "agree," "neutral," "disagree," or "strongly disagree" for items 5 and 6 . Answers of yes to items 1 through 4 and "agree" or "strongly agree" to items 5 and 6 were considered a favorable attitude (unitary score $=1$ ), whereas all other answers ("no," "not sure," "neutral," "disagree," and "strongly disagree") were assumed to be an unfavorable attitude (unitary score $=0$ ). A favorability score (range $=0-6$ ) indicating the likelihood of a favorable attitude toward e-cigarette clinical use was computed as the number of statements when the participant exhibited a positive attitude, ie the sum of unitary scores. This scoring system was evaluated by analyzing the reliability and the correlations between the total score and each item separately, as indicated in the statistical methods.

\section{Study Procedure}

The questionnaire was administered online via the SurveyMonkey platform (SurveyMonkey Europe UC). The web link was sent via email to all selected participants and included a notification about the study objectives and response confidentiality and a statement of explicit consent to participate. Potential participants were advised that the study results would be involved in a statistical analysis and would aim for publication in a peer-reviewed journal.

\section{Statistical Methods}

Data were downloaded as a Microsoft Excel spreadsheet that was exported as an SPSS (SPSS version 21.0 for Windows, SPSS Inc., Chicago, IL, USA) database for statistical analysis. Descriptive statistics were used to summarize participants' characteristics as well as patterns of answering for the different parts of the questionnaire. The favorability scale (six items) underwent reliability analysis by calculating Cronbach's alpha and estimating alpha by the deletion of each item. In essence, Cronbach's alpha is a widely used reliability coefficient to measure the internal consistency of a set of questionnaire items via exploring how closely related they are as a single group. ${ }^{11}$ Further, Pearson's correlation was used to analyze the correlation of the favorability score with the scores for each item. The favorability score was analyzed as a binary variable (favorable vs not favorable), by assuming that having a positive attitude towards most items would reflect an overall favorable attitude. Factors associated with a favorable attitude were analyzed using the chi-square test for categorical variables and independent $t$-test for continuous variables, including age. Multivariate binary logistic regression was used to analyze independent factors of favorable inclination to use e-cigarettes clinically. Predictor variables included the significantly associated variables from the univariate correlation analyses. The results were presented as odds ratio (OR) with $95 \%$ confidence interval (CI). A $p$-value of $<0.05$ was considered to reject the null hypothesis.

\section{Results}

\section{Participant Demographics and Academic Characteristics}

A total of 399 students responded to the questionnaire, with a mean (standard deviation [SD]) age of 21.75 (2.91), and with $55.4 \%$ females and $96.5 \%$ Saudi. A majority were single $(92.0 \%)$, without children $(95.0 \%)$, and living in Jeddah (92.7\%). Academically, the majority had a very high $(48.6 \%)$ or high (44.4\%) GPA (Table 1). 
Table I Participant Demographics ( $N=399)$

\begin{tabular}{|c|c|c|c|}
\hline Parameter & Category & Frequency & Percentage \\
\hline \multicolumn{4}{|l|}{ Sociodemographic factors } \\
\hline Age & Mean, SD & 21.75 & 2.91 \\
\hline \multirow[t]{2}{*}{ Gender } & Male & 178 & 44.6 \\
\hline & Female & 221 & 55.4 \\
\hline \multirow[t]{2}{*}{ Nationality } & Saudi & 385 & 96.5 \\
\hline & Non-Saudi & 14 & 3.5 \\
\hline \multirow[t]{3}{*}{ Marital status } & Single & 367 & 92.0 \\
\hline & Married & 30 & 7.5 \\
\hline & Divorced & 2 & 0.5 \\
\hline \multirow[t]{5}{*}{ No. children } & 0 & 379 & 95.0 \\
\hline & 1 & 11 & 2.8 \\
\hline & 2 & 5 & 1.3 \\
\hline & 3 & 3 & 0.8 \\
\hline & 6 & 1 & 0.3 \\
\hline \multirow[t]{3}{*}{ Parents' marital status } & Married & 336 & 84.2 \\
\hline & Divorced & 35 & 8.8 \\
\hline & Widowed & 28 & 7.0 \\
\hline \multirow[t]{3}{*}{ Monthly income } & $<3000$ & 13 & 3.3 \\
\hline & $3000-10,000$ & 69 & 17.3 \\
\hline & $>10,000$ & 317 & 79.4 \\
\hline \multirow[t]{2}{*}{ Residence place } & Jeddah & 370 & 92.7 \\
\hline & Other city & 29 & 7.3 \\
\hline \multirow[t]{3}{*}{ Living situation } & With family & 359 & 90.0 \\
\hline & With friends & 10 & 2.5 \\
\hline & Alone & 30 & 7.5 \\
\hline \multirow[t]{3}{*}{ Housing } & Own house & 291 & 72.9 \\
\hline & Rented & 87 & 21.8 \\
\hline & Student dormitory & 21 & 5.3 \\
\hline \multicolumn{4}{|l|}{ Academic factors } \\
\hline \multirow[t]{5}{*}{ Academic year } & 2nd & 95 & 23.8 \\
\hline & $3 r d$ & 76 & 19.0 \\
\hline & 4th & 98 & 24.6 \\
\hline & 5 th & 66 & 16.5 \\
\hline & 6th & 64 & 16.0 \\
\hline
\end{tabular}


Table I (Continued).

\begin{tabular}{|l|l|c|c|}
\hline Parameter & Category & Frequency & Percentage \\
\hline GPA & $4.5-5$ & 194 & 48.6 \\
\cline { 2 - 5 } & $3.5-4.49$ & 177 & 44.4 \\
\cline { 2 - 5 } & $2.5-3.49$ & 27 & 6.8 \\
\cline { 2 - 5 } & $<2.5$ & 1 & 0.3 \\
\hline
\end{tabular}

Abbreviation: GPA, grade point average.

\section{Clinical Data and Exposure to Smoking and e-Smoking}

Of the participants, $22.1 \%$ declared having chronic diseases, with asthma (6.5\%), anemia (4.5\%), and headache $(4.0 \%)$ the three most frequently reported diseases. Smoking history showed current smokers (19.8\%) and ex-smokers (6.5\%); e-cigarettes had been tried by $36.6 \%$, and $11.5 \%$ are currently using them (Table 2).

\section{Knowledge About and Attitudes Toward e-Cigarettes and e-Smoking}

A minority $(13.5 \%)$ of the participants believed that e-cigarettes are FDA-approved for smoking cessation, while approximately one-third believed that e-smoking lowers the risk of cancer $(31.1 \%)$ and could be a helpful aid for smoking cessation (31.1\%). Further, 35.9\% agreed or strongly agreed that e-cigarettes would be better for their patients than tobacco products, and $17.5 \%$ declared being likely to recommend e-smoking to their patients as a smoking cessation method. However, $50.6 \%$ agreed that e-cigarettes are addictive. Other items showed areas of very high concern for education regarding e-cigarettes $(90.9 \%)$, including relatively low levels of confidence in counseling patients about both traditional (51.6\%) and e-cigarettes (35.1\%) (Table 3). Social media (77.4\%) represented the primary source of information about e-cigarettes, followed by online (26.6\%) and TV advertisements (9.8\%) (Figure 1).

\section{Favorability of Clinical Usage of e-Cigarettes}

The six-item scale underwent reliability analysis and showed intermediate reliability, with Cronbach's alpha
$=0.676$. After the deletion of item 6 ("E-cigarettes are addictive"), the reliability of the scale was enhanced to 0.746. Further, Pearson's correlation showed that among all items, item 6 had the weakest correlation with the 6item scale score (Table 4). Thus, item 6 was rejected, and the level of favorability (range $=0-5$ ) was calculated as the sum of unitary scores from the other five items. By assuming a cutoff of $>2$ out 5, 23.6\% (95\% $\mathrm{CI}=19.5 \%, 28.0 \%)$ of the participants would be in favor of the clinical usage of e-cigarettes in smoking cessation.

\section{Factors Associated with a Favorable Attitude Toward Clinical Usage of e-Cigarettes}

Males were more inclined to be in favor of the clinical usage of e-cigarettes for smoking cessation than females $(33.7 \%$ vs $15.4 \%)$, and the difference was statistically significant $(p<0.001)$ (Table 5). Both current smokers (34.2\%) and ex-smokers (38.5\%) were more likely to be in favor of clinical usage of e-smoking when compared to nonsmokers $(19.4 \%, p=$ 0.004). Further, participants who had ever tried e-smoking ( $36.3 \%$ vs $16.2 \%$ ), current users of e-cigarettes $(52.2 \%$ vs $19.8 \%)$, and those who had e-smokers among their close acquaintances (32.0\% vs $14.5 \%)$ were more likely to be in favor of the clinical usage of e-smoking, and the comparisons were statistically significant (Table 6).

Multivariate binary regression showed that being male $(\mathrm{OR}=2.39, p=0.001)$ or ever having tried e-smoking $(\mathrm{OR}=1.17, p=0.015)$ were the independent factors associated with a favorable attitude and beliefs regarding the clinical usage of e-smoking (Table 7). 
Table 2 Clinical Data and Exposure to Smoking and e-Smoking $(N=399)$

\begin{tabular}{|c|c|c|c|}
\hline Parameter & Category & Frequency & Percentage \\
\hline \multicolumn{4}{|l|}{ Clinical data } \\
\hline Weight & Mean, SD & 66.31 & 19.81 \\
\hline Height & Mean, SD & 161.89 & 20.91 \\
\hline \multirow[t]{6}{*}{ BMI Class } & Underweight $(<18.5)$ & 61 & 15.3 \\
\hline & Normal weight (18.5--24.9) & 197 & 49.4 \\
\hline & Overweight (25.0--29.9) & 79 & 19.8 \\
\hline & Class I obesity (30.0-34.9) & 39 & 9.8 \\
\hline & Class II obesity (35.0-39.9) & 16 & 4.0 \\
\hline & Class II obesity $(?(>40.0))$ & 7 & 1.8 \\
\hline \multirow[t]{12}{*}{ Chronic disease } & No & 311 & 77.9 \\
\hline & Yes & 88 & 22.1 \\
\hline & Asthma & 26 & 6.5 \\
\hline & Anemia & 18 & 4.5 \\
\hline & Headache & 16 & 4.0 \\
\hline & Hypertension & 8 & 2.0 \\
\hline & Diabetes & 8 & 2.0 \\
\hline & Gastroesophageal reflux & 6 & 1.5 \\
\hline & Multiple sclerosis & 5 & 1.3 \\
\hline & Inflammatory bowel disease & 4 & 1.0 \\
\hline & Kidney disease & 2 & 0.5 \\
\hline & Other ${ }^{\S}$ & 25 & 6.3 \\
\hline \multirow[t]{5}{*}{ No. Diseases } & 0 & 314 & 78.7 \\
\hline & 1 & 65 & 16.3 \\
\hline & 2 & 9 & 2.3 \\
\hline & 3 & 9 & 2.3 \\
\hline & 4 & 2 & 0.5 \\
\hline \multirow[t]{2}{*}{ Family history of mental disorder } & No & 294 & 73.7 \\
\hline & Yes & 105 & 26.3 \\
\hline \multicolumn{4}{|l|}{ Exposure to smoking and e-smoking } \\
\hline \multirow[t]{3}{*}{ Smoking status } & Smoker & 79 & 19.8 \\
\hline & Nonsmoker & 294 & 73.7 \\
\hline & Ex-smoker & 26 & 6.5 \\
\hline \multirow[t]{2}{*}{ Immediate family member smokes } & No & 159 & 39.8 \\
\hline & Yes & 240 & 60.2 \\
\hline
\end{tabular}


Table 2 (Continued).

\begin{tabular}{|c|c|c|c|}
\hline Parameter & Category & Frequency & Percentage \\
\hline \multirow[t]{7}{*}{ Ever e-smoked } & No & 253 & 63.4 \\
\hline & Yes & 146 & 36.6 \\
\hline & $<$ Once per month & 65 & 16.3 \\
\hline & Monthly & 15 & 3.8 \\
\hline & Weekly & 16 & 4.0 \\
\hline & Daily & 44 & 11.0 \\
\hline & Not specified & 6 & 1.5 \\
\hline \multirow[t]{2}{*}{ Current e-smoker } & No & 353 & 88.5 \\
\hline & Yes & 46 & 11.5 \\
\hline \multirow[t]{2}{*}{ Family member or friend uses e-cigarettes } & No & 193 & 48.4 \\
\hline & Yes & 206 & 51.6 \\
\hline
\end{tabular}

Note: ${ }^{\S}$ Other diseases included: malignancy (3 participants), cardiac diseases (2), arthritis (I), immunodeficiency (I), not specified (I8). Abbreviations: BMI, body mass index; SD, standard deviation.

\section{Discussion}

\section{Summary of Findings}

This cross-sectional study explored the likelihood that medical students would be in favor of the clinical use of e-cigarettes in smoking cessation by exploring specific knowledge and attitudes regarding e-cigarettes. The model used in this study showed acceptable reliability and demonstrated that approximately one-quarter of the students were likely to be favorably inclined toward the clinical usage of e-smoking as a smoking cessation method or as a risk reduction strategy among smokers. Further, this favorability was significantly predicted by male gender and previous personal e-smoking experience. In addition, the study highlighted substantial gaps in knowledge and confidence regarding smoking and e-smoking among these medical students, indicating the need for more adequate education regarding these topics. Secondarily, the prevalence of previous experience and current e-cigarette use were estimated as $36.6 \%$ and $11.5 \%$, respectively.

\section{Are e-Cigarettes Approved by the National Regulations in Different Countries?}

More specifically, $13.5 \%$ of the students believed that e-cigarettes have been approved by the FDA for smoking cessation, and a majority (70.7\%) were not sure. In Saudi
Arabia, the sale and marketing of e-cigarettes are banned by the decision of health ministries of the Gulf countries, which is the case in the United Arab Emirates. ${ }^{12}$ International health authorities such as the World Health Organization and the American Heart Association, along with most major countries, discourage the promotion of e-cigarettes as an alternative to established smoking cessation medications. Consequently, health care professionals, including physicians, nurses, and medical students, should be educated regarding the legal status of e-cigarettes, most notably concerning its clinical use, in order to provide proper counseling to patients and the general population. In developed countries, the legal dimensions of e-cigarette use may vary across countries in some specific aspects; however, they share core similarities. In the United States, initial attempts to regulate e-cigarettes as pharmaceutical products were inconclusive, and no specific regulations were issued. Instead, e-cigarettes were subjected to common tobacco product regulation, which varies between US states and cities. In line with this resolution, the FDA applied a prohibition on the sale of e-cigarettes to minors, instructed there to be a health warning on the packaging, and banned the marketing of e-cigarettes as a safer alternative to traditional tobacco products or as a smoking cessation strategy. ${ }^{13,14}$ More recently, the FDA disclosed a regulatory plan to ban the sale of fruit-flavored e-cigarettes, given that such products represent a stepping stone 
Table 3 Knowledge and Attitudes Toward e-Cigarettes and e-Smoking ( $N=399)$

\begin{tabular}{|c|c|c|c|}
\hline Item & Answer & $\mathbf{n}$ & $\%$ \\
\hline \multirow[t]{3}{*}{ Are e-cigarettes approved by the FDA for smoking cessation? ${ }^{\S}$} & No & 63 & 15.8 \\
\hline & Not Sure & 282 & 70.7 \\
\hline & Yes & 54 & 13.5 \\
\hline \multirow{3}{*}{$\begin{array}{l}\text { Do you believe that e-cigarettes lower the risk of cancer for patients who use } \\
\text { them instead of smoking traditional cigarettes? } \$\end{array}$} & No & 167 & 41.9 \\
\hline & Not Sure & 108 & 27.1 \\
\hline & Yes & 124 & 31.1 \\
\hline \multirow[t]{3}{*}{ Do you believe e-cigarettes are a helpful aid for smoking cessation? $?^{\S}$} & No & 161 & 40.4 \\
\hline & Not Sure & 114 & 28.6 \\
\hline & Yes & 124 & 31.1 \\
\hline \multirow{3}{*}{$\begin{array}{l}\text { If you were to see a patient who smokes cigarettes today, would you } \\
\text { recommend the use of e-cigarettes as a smoking cessation method? }\end{array}$} & No & 215 & 53.9 \\
\hline & Not Sure & 114 & 28.6 \\
\hline & Yes & 70 & 17.5 \\
\hline \multirow{5}{*}{$\begin{array}{l}\text { Despite the unknowns, the use of e-cigarettes is better for my patients than } \\
\text { smoking tobacco products } \S\end{array}$} & Strongly agree & 37 & 9.3 \\
\hline & Agree & 106 & 26.6 \\
\hline & Neutral & $14 \mid$ & 35.3 \\
\hline & Disagree & 80 & 20.1 \\
\hline & Strongly disagree & 35 & 8.8 \\
\hline \multirow[t]{5}{*}{ E-cigarettes are addictive ${ }^{\S}$} & Strongly agree & 48 & 12.0 \\
\hline & Agree & 154 & 38.6 \\
\hline & Neutral & $14 \mid$ & 35.3 \\
\hline & Disagree & 49 & 12.3 \\
\hline & Strongly disagree & 7 & 1.8 \\
\hline \multirow[t]{5}{*}{ It is important for physicians to be educated about e-cigarettes. } & Strongly agree & 206 & 51.6 \\
\hline & Agree & 157 & 39.3 \\
\hline & Neutral & 28 & 7.0 \\
\hline & Disagree & 5 & 1.3 \\
\hline & Strongly disagree & 3 & 0.8 \\
\hline \multirow{5}{*}{$\begin{array}{l}\text { As a student, I feel confident about my ability to discuss traditional cigarette use } \\
\text { with my patients. }\end{array}$} & Strongly agree & 56 & 14.0 \\
\hline & Agree & 150 & 37.6 \\
\hline & Neutral & 114 & 28.6 \\
\hline & Disagree & 67 & 16.8 \\
\hline & Strongly disagree & 12 & 3.0 \\
\hline
\end{tabular}

(Continued) 
Table 3 (Continued).

\begin{tabular}{|c|c|c|c|}
\hline Item & Answer & $\mathbf{n}$ & $\%$ \\
\hline \multirow{5}{*}{$\begin{array}{l}\text { As a student, I feel confident about my ability to discuss e-cigarette use with my } \\
\text { patients. }\end{array}$} & Strongly agree & 40 & 10.0 \\
\hline & Agree & 100 & 25.1 \\
\hline & Neutral & 128 & 32.1 \\
\hline & Disagree & 105 & 26.3 \\
\hline & Strongly disagree & 26 & 6.5 \\
\hline \multirow{2}{*}{$\begin{array}{l}\text { In your opinion, have you received adequate education about e-cigarettes in } \\
\text { medical school? }\end{array}$} & No & 85.7 & 342 \\
\hline & Yes & 14.3 & 57 \\
\hline
\end{tabular}

Note: ${ }^{\S}$ Items comprising the favorability scale.

to smoking, which may increase the risk of addiction among teenagers. ${ }^{15,16}$ In the United Kingdom, e-cigarette products are subject to national and European Union (EU) regulations, notably the EU Tobacco Products Directive and the Medicines and Healthcare Products Regulatory Agency, which differentiate between products containing less than $20 \mathrm{mg}$ of nicotine and those containing more. Government taxes are applied, public advertising is restricted to sale points, and any claims for health benefits are banned. Further, any images or messages referring to or suggestive of traditional tobacco products were strictly banned from e-cigarette advertising, thereby preventing the indirect promotion of tobacco products. On the other hand, the UK government adopted several policies encouraging e-smoking over traditional smoking, such as legalizing indoor vaping, notably in National Health Service hospitals for both visitors and patients. ${ }^{17}$ In Canada, e-cigarettes are legalized for sale and consumption, with some restrictions on age, advertising, and public use. The Canadian government stated, The Tobacco and Vaping Products Act provides a balanced framework for vaping products by protecting youth and non-users of tobacco products from nicotine addiction and inducements to use tobacco, while allowing adults to legally access vaping products as a less harmful alternative to tobacco. In the meantime, efforts have been undertaken by Health Canada to regulate the use of flavors, packaging and labeling, and advertising. ${ }^{16}$

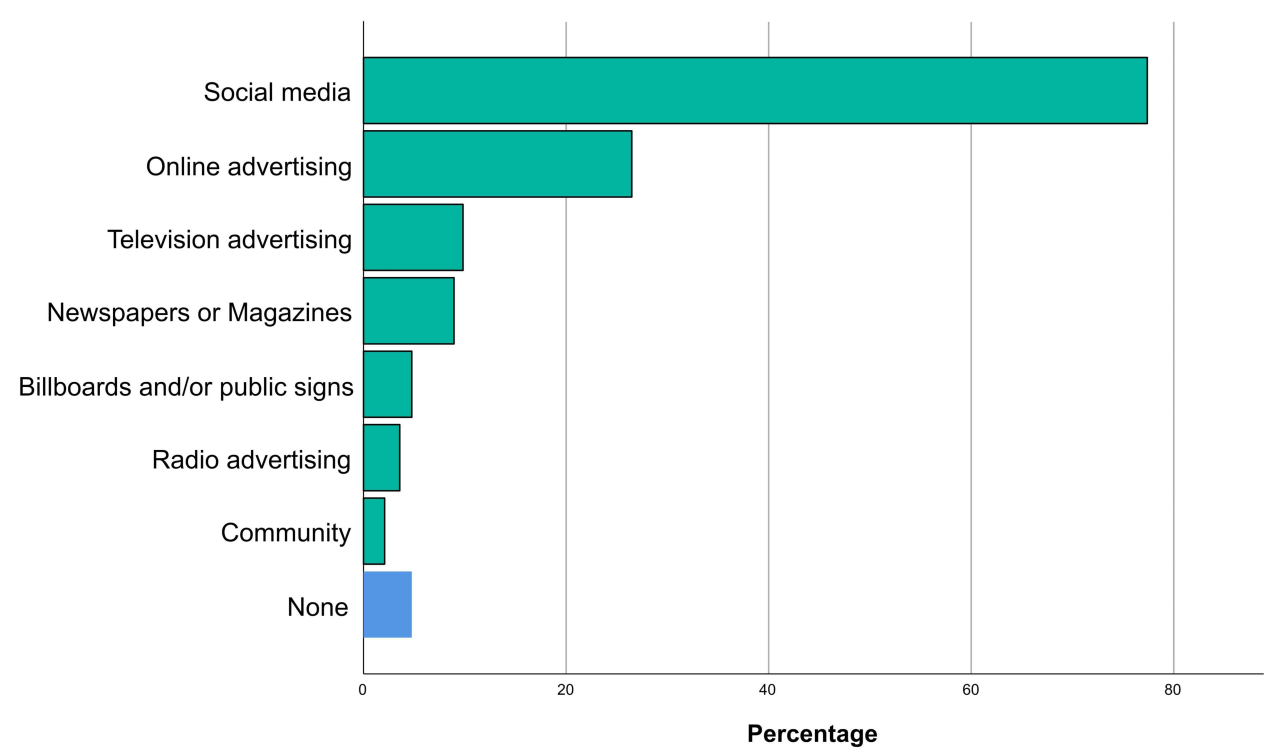

Figure I Sources of knowledge about e-cigarettes. 
Table 4 Reliability Testing of the Favorability Scale

\begin{tabular}{|c|c|c|c|c|}
\hline \multirow[t]{2}{*}{ Scale Items } & \multicolumn{2}{|c|}{$\begin{array}{l}\text { Endorsed } \\
\text { Item }\end{array}$} & \multirow[t]{2}{*}{$\begin{array}{l}\text { Correlation Between Item } \\
\text { Score and Total Score }\end{array}$} & \multirow[t]{2}{*}{$\begin{array}{l}\text { Cronbach's Alpha } \\
\text { without the Item }\end{array}$} \\
\hline & $\mathbf{n}$ & $\%$ & & \\
\hline Are e e-cigarettes approved by the FDA for smoking cessation? & 54 & 13.5 & 0.437 & 0.680 \\
\hline $\begin{array}{l}\text { Do you believe e-cigarettes lower the risk of cancer compared to } \\
\text { smoking traditional cigarettes? }\end{array}$ & 124 & 31.1 & 0.714 & 0.591 \\
\hline $\begin{array}{l}\text { Do you believe e-cigarettes are a helpful aid for smoking } \\
\text { cessation? }\end{array}$ & 124 & 31.1 & 0.750 & 0.570 \\
\hline $\begin{array}{l}\text { Would you recommend the use of e-cigarettes as a smoking } \\
\text { cessation method to your patients? }\end{array}$ & 70 & 17.5 & 0.689 & 0.599 \\
\hline $\begin{array}{l}\text { Despite the unknowns, the use of e-cigarettes is better for my } \\
\text { patients than smoking tobacco products. }\end{array}$ & 143 & 35.8 & 0.730 & 0.584 \\
\hline E-cigarettes are addictive.* & 197 & 49.4 & 0.396 & 0.746 \\
\hline
\end{tabular}

Note: *Inversely endorsed item, meaning favorable attitude was assumed to be "strongly disagree" and or "disagree" answers.

\section{Do e-Cigarettes Lower the Risk of Cancer Compared to Smoking Traditional Cigarettes?}

In the present study, one-third of the respondents believed that e-smoking reduces the risk of cancer when used as an alternative to traditional cigarettes. Although it is known that e-cigarette vapors contain significantly lower levels of carcinogenic toxicants as compared to traditional tobacco,18 there is strong debate surrounding the harmfulness of e-cigarettes compared to traditional cigarettes and whether they are associated with reduced health risks, especially regarding lung cancer and other tobacco-related malignancies.

A survey among Korean lung cancer experts, including pulmonologists, thoracic surgeons, and medical and radiology oncologists, showed that most $(>75 \%)$ believed that e-smoking does not represent a safer alternative to traditional tobacco or smokeless tobacco. Additionally, twothirds alleged that discussing such issues with patients would encourage its use. Consequently, approximately $80 \%$ of the respondents disapproved of e-smoking as a smoking cessation method and did not recommend its clinical use for patients. ${ }^{19}$

Indeed, the high temperatures reached in e-cigarette devices result in transforming the liquid mixtures they contain into highly toxic substances. ${ }^{20,21}$ A German research team analyzed 28 liquids from seven e-cigarette brands available on the German market. Among the components detected, glycerol and propylene glycol were the most frequently used solvents except for five samples, where they were substituted by ethylene glycol, which has more toxic features. Other hazardous substances such as coumarin and acetamide were detected as additives. Specifically, after a certain period of use of a widely used e-cigarette brand, substantial amounts of formaldehyde, acetaldehyde, and propionaldehyde were formed, and concentrations of these substances increased as a function of vaping time until they reached levels comparable to those observed with traditional tobacco. ${ }^{22}$ Inhalation of formaldehyde is highly associated with lung cancer, and some authors have estimated that e-smoking could result in a 5- to 15 times higher lifetime cancer risk than traditional smoking owing to the presence in vaping liquids of formaldehyde-releasing agents that deposit more proficiently in the respiratory tract than does the gaseous formaldehyde contained in traditional cigarettes. ${ }^{21}$

Consequently, the carcinogenic risk is more than ever a concern, preventing the clinical use of e-cigarettes in tobacco cessation and disproving it as a risk reduction strategy. An interesting study by Stephens ${ }^{23}$ assessed the relative cancer risk of vaporized nicotine products and traditional tobacco products. The author used a literature-based model of chemical emissions and inhalation unit by type of vaporized product and converted it into a lifetime cancer risk using comparable daily consumptions. In a five-level magnitude from pure air to traditional tobacco smoke, most e-cigarettes were 
Table 5 Demographic and Academic Factors Associated with Favorable Clinical Attitude Toward e-Smoking $(\mathrm{N}=399)$

\begin{tabular}{|c|c|c|c|c|}
\hline \multirow[t]{2}{*}{ Parameter } & \multirow[t]{2}{*}{ Category } & \multicolumn{2}{|c|}{ Favorable } & \multirow[t]{2}{*}{$p$-value } \\
\hline & & No $(n, \%)$ & Yes (n, \%) & \\
\hline \multicolumn{5}{|c|}{ Sociodemographic factors } \\
\hline Age & Mean, SD & $21.81(3.15)$ & $21.57(1.92)$ & 0.499 \\
\hline \multirow[t]{2}{*}{ Gender } & Male & $118(66.3)$ & $60(33.7)$ & \\
\hline & Female & $187(84.8)$ & $34(15.4)$ & $<0.001 *$ \\
\hline \multirow[t]{2}{*}{ Nationality } & Non-Saudi & $294(76.4)$ & 91 (23.6) & \\
\hline & Saudi & II (78.8) & $3(21.4)$ & $1.000 \mathrm{~F}$ \\
\hline \multirow[t]{2}{*}{ Marital status } & Single & $285(77.7)$ & $82(22.3)$ & \\
\hline & Married or divorced & $20(32.5)$ & $12(37.5)$ & 0.053 \\
\hline \multirow[t]{2}{*}{ No. children } & 0 & $292(77.0)$ & $87(23.0)$ & \\
\hline & $1+$ & $13(65.0)$ & $7(35.0)$ & 0.216 \\
\hline \multirow[t]{3}{*}{ Parents' marital status } & Married & $254(75.6)$ & $82(24.4)$ & \\
\hline & Divorced & $28(80.0)$ & $7(20.0)$ & \\
\hline & Widowed & $23(82.1)$ & $5(17.9)$ & 0.642 \\
\hline \multirow[t]{3}{*}{ Monthly income } & $<3000$ & $9(69.2)$ & $4(30.8)$ & \\
\hline & $3000-10,000$ & $56(81.2)$ & $13(18.8)$ & \\
\hline & $>10,000$ & $240(75.7)$ & $77(24.3)$ & 0.516 \\
\hline \multirow[t]{2}{*}{ Residence location } & Jeddah & $287(77.6)$ & $83(22.4)$ & \\
\hline & Other city & $18(62.1)$ & II (37.9) & 0.058 \\
\hline \multirow[t]{3}{*}{ Living situation } & With family & $274(76.3)$ & $85(23.7)$ & \\
\hline & With friends & $8(80.0)$ & $2(20.0)$ & \\
\hline & Alone & $23(76.7)$ & $7(23.3)$ & 0.964 \\
\hline \multirow[t]{3}{*}{ Housing } & Own house & $222(76.3)$ & $69(23.7)$ & \\
\hline & Rent & $65(74.7)$ & $22(25.3)$ & \\
\hline & Student dormitory & $18(85.7)$ & $3(14.3)$ & 0.562 \\
\hline \multicolumn{5}{|l|}{ Academic factors } \\
\hline \multirow[t]{5}{*}{ Academic year } & $2 n d$ & 71 (74.7) & $24(25.3)$ & \\
\hline & $3 r d$ & $57(75.0)$ & $19(25.0)$ & \\
\hline & 4th & $80(81.6)$ & $18(18.4)$ & \\
\hline & 5 th & $48(72.7)$ & $18(27.3)$ & \\
\hline & 6th & $49(76.6)$ & $15(23.4)$ & 0.697 \\
\hline \multirow[t]{4}{*}{ GPA } & $4.5-5$ & $152(78.4)$ & $42(21.6)$ & \\
\hline & $3.5-4.49$ & $|3|(74.0)$ & $46(26.0)$ & \\
\hline & $2.5-3.49$ & $21(77.8)$ & $6(22.2)$ & \\
\hline & $<2.5$ & I (100.0) & $0(0.0)$ & 0.727 \\
\hline
\end{tabular}

Note: *Indicates statistical significance.

Abbreviation: GPA, grade point average. 
Table 6 Favorable Attitudes Toward e-Smoking with Clinical Factors and Exposure to Smoking and e-Smoking ( $N=399)$

\begin{tabular}{|c|c|c|c|c|}
\hline \multirow[t]{2}{*}{ Parameter } & \multirow[t]{2}{*}{ Category } & \multicolumn{2}{|c|}{ Favorable } & \multirow{2}{*}{$\frac{\text { Favorable }}{\text { p-value }}$} \\
\hline & & No $(n, \%)$ & Yes (n, \%) & \\
\hline \multicolumn{5}{|l|}{ Clinical data } \\
\hline \multirow[t]{2}{*}{ BMI class } & $\begin{array}{l}\text { Normal or } \\
\text { underweight }\end{array}$ & $204(79.1)$ & $54(20.9)$ & \\
\hline & Overweight or obese & I0I (7I.6) & $40(28.4)$ & 0.094 \\
\hline \multirow[t]{2}{*}{ Chronic disease } & No & $233(74.9)$ & $78(25.1)$ & \\
\hline & Yes & $72(81.8)$ & $16(18.2)$ & 0.178 \\
\hline \multirow[t]{2}{*}{ Family history of mental disorder } & No & $226(76.9)$ & $68(23.1)$ & \\
\hline & Yes & $79(75.2)$ & $26(24.8)$ & 0.735 \\
\hline \multicolumn{5}{|l|}{ Exposure to smoking and e-smoking } \\
\hline \multirow[t]{3}{*}{ Smoking status } & Nonsmoker & $237(80.6)$ & $57(19.4)$ & \\
\hline & Ex-smoker & $16(6 \mid .5)$ & $10(38.5)$ & \\
\hline & Current smoker & $52(65.8)$ & $27(34.2)$ & $0.004 *$ \\
\hline \multirow[t]{2}{*}{ Current Smoking status } & Never smoked & $237(80.6)$ & $57(19.4)$ & \\
\hline & Current or ex-smoker & $68(64.8)$ & $37(35.2)$ & $0.001 *$ \\
\hline \multirow[t]{2}{*}{ Immediate family member smokes } & No & $124(78.0)$ & $35(22.0)$ & \\
\hline & Yes & |8| (75.4) & $59(24.6)$ & 0.554 \\
\hline \multirow[t]{2}{*}{ Ever e-smoked } & No & $212(83.8)$ & $4 \mid(16.2)$ & \\
\hline & Yes & $93(63.7)$ & $53(36.3)$ & $<0.001 *$ \\
\hline \multirow[t]{2}{*}{ Current e-smoker } & No & $283(80.2)$ & $70(19.8)$ & \\
\hline & Yes & $22(47.8)$ & $24(52.2)$ & $<0.001 *$ \\
\hline \multirow[t]{2}{*}{ Family member or friend uses e-cigarettes } & No & $165(85.5)$ & $28(14.5)$ & \\
\hline & Yes & $140(68.0)$ & $66(32.0)$ & $<0.001 *$ \\
\hline
\end{tabular}

Note: *Statistically significant result $(p<0.05)$

Abbreviation: BMI, body mass index.

estimated to have potencies $<1 \%$ of traditional tobacco; while products susceptible to generating high levels of carbonyl had higher cancer potencies. Additionally, the lifetime risk of cancer was estimated to be lowest in nicotine inhalers than normal power e-cigarettes, while it was relatively higher in heat-not-burn products. The author called for high levels of caution with the use of such products, highlighting the existence of hazardous combinations of liquid formulation and consumption behaviors. $^{23}$ In an animal lung model, Canistro et $\mathrm{al}^{24}$ demonstrated that e-cigarette vapors induced strong carcinogenic effects, including boosting the activity of a carcinogen-bioactivating enzyme, increasing oxygen free radical production, and enhancing DNA damage at both the chromosomal and genetic levels. Such findings provide evidence of the carcinogenic risk associated with e-cigarettes, especially among youngsters and vulnerable users. ${ }^{24}$ Data from in vitro studies have confirmed the harmful effects of e-cigarettes on cells, including alteration of gene expressions, notably those involved in apoptosis, hypoxia, inflammation, and biosynthesis pathways. However, these changes were demonstrated to be less remarkable than those observed with traditional cigarette smoke, even at higher nicotine concentrations, leading to cautious conclusions. ${ }^{25-27}$ 
Table 7 Predictors of Favorable Attitude Toward e-Smoking (Regression)

\begin{tabular}{|c|c|c|c|c|c|}
\hline \multirow{2}{*}{$\begin{array}{l}\text { Predictor } \\
\text { Gender }\end{array}$} & \multirow{2}{*}{$\begin{array}{l}\text { Category } \\
\text { Male }\end{array}$} & \multirow{2}{*}{$\begin{array}{l}\text { OR } \\
2.39\end{array}$} & \multicolumn{2}{|c|}{$95 \% \mathrm{Cl}$} & \multirow{2}{*}{$\frac{p \text {-value }}{0.00 I^{*}}$} \\
\hline & & & 1.42 & 4.01 & \\
\hline & Female & Ref & -- & - & - \\
\hline \multirow[t]{2}{*}{ Smoking status } & Never smoker & Ref & - & - & - \\
\hline & Ever smoked & 0.80 & 0.40 & 1.58 & 0.513 \\
\hline \multirow[t]{2}{*}{ Ever e-smoked } & No & Ref & - & - & - \\
\hline & Yes & 2.25 & 1.17 & 4.32 & $0.015^{*}$ \\
\hline \multirow[t]{2}{*}{ Current e-smoker } & No & Ref & - & - & - \\
\hline & Yes & 2.09 & 0.96 & 4.56 & 0.065 \\
\hline \multirow[t]{2}{*}{ Close person e-smoker } & No & Ref & - & - & - \\
\hline & Yes & 1.44 & 0.81 & 2.57 & 0.218 \\
\hline
\end{tabular}

Notes: Multivariate binary regression. *Statistically significant result $(p<0.05)$.

Abbreviations: $\mathrm{OR}$, odds ratio; $\mathrm{Cl}$, confidence interval; Ref, category used as reference to calculate the $\mathrm{OR}$.

\section{e-Cigarettes for Smoking Cessation or as a Risk Reduction Strategy}

Regarding specific items related to e-cigarette usefulness in smoking cessation, almost one-third of the participants in the present study agreed with the theoretical statement and $28.6 \%$ were not sure, while $17.5 \%$ declared that they would recommend it to their patients as a smoking cessation method. Additionally, 35.9\% subscribed to the point of view that e-cigarettes are better for patients than traditional tobacco products. Given the complexity of the scientific debate, several dimensions of addiction, toxicity, and public health should be considered to address this issue.

A meta-analysis pooling data from 38 controlled studies, including cohort and cross-sectional studies and clinical trials, demonstrated an adverse effect of e-cigarettes on smoking cessation, with $28 \%$ fewer quitting among e-cigarette users when compared with non-users. ${ }^{28}$ The expert opinions in the international body of literature transmits a persistent skepticism among health professionals regarding the use of e-cigarettes in smoking cessation. In Netherlands, a majority of physicians and tobacco counselors have declared they are advising their patients against vaping, although they recognize it as being less harmful than traditional tobacco. ${ }^{29}$ In the United States, a predominantly negative view of e-smoking was found among professionals, owing to the lack of strong evidence for its efficacy and resulting in dissuasive advice to patients and the population by general practitioners and quit line professionals. ${ }^{30,31}$ In the south-west of England, a qualitative study explored attitudes among 25 smoking cessation service staff members about e-cigarette friendly services. Attitudes ranged from active engagement in promoting e-smoking within the service for reducing the risks related to smoking, especially among the unfavored patients, to complete reluctance justified by fundamental ethics of duty of care, considering the risk of the addictiveness of e-cigarettes and the controversy surrounding the issue, in addition to the lack of a strong public health leadership addressing the issue. ${ }^{32}$

Aside from this dominant negative opinion, some studies have revealed more ambiguous attitudes; notably, a US study showed that more than $50 \%$ of patients reported being directly or indirectly advised by their personal physicians to use e-cigarettes as a supplemental aid for smoking cessation. ${ }^{33}$ Another qualitative study showed that a high percentage of American physicians would be amenable to recommending e-cigarettes to their patients, subject to new convincing evidence regarding long-term effects and safety. ${ }^{34}$ Finally, a US study involving junior physicians found that those who were likely to recommend e-smoking therapeutically were doing so with a harm reduction approach rather than as a quitting method. ${ }^{35}$ Consequently, negative attitudes regarding the clinical and therapeutic use of e-cigarettes are likely to be the norm among health professionals, and particularly cessation counselors, while shifts in opinions may occur under eventual novel evidence. From the patient's perspective, a study involving individuals who successfully used e-cigarettes to quit smoking collected their advice to smokers about how to eventually use e-cigarettes to support a smoking cessation attempt. Participants recommended combining the suitable device with flavor and finding the appropriate nicotine dosage. They also suggested continuing to smoke and vape temporarily, if needed, and expecting an improvement in health after a total switch to 
e-smoking. Finally, they encouraged interacting with e-smokers, notably in online dedicated forums, to find timely support and increase the hope of success. ${ }^{36}$

\section{Are e-Cigarettes Addictive?}

Students' beliefs regarding the addictiveness of e-cigarettes were mixed; $50.6 \%$ agreed with the statement, while the remaining students were neutral or disagreed. It is a common belief that e-cigarettes are less addictive than traditional cigarettes. However, several studies have shown high levels of dependency among e-cigarettes users, sometimes surpassing those of traditional tobacco products. One cross-sectional study showed a two-fold increase on a nicotine dependency index among e-smokers and a 1.5 -fold increase among dual e-cigarette and traditional cigarette smokers. Such observations highlight the addictive effects of e-cigarettes and suggest the concurrence of other behavioral factors of addiction that are specifically associated with e-smoking, such as a tendency for daily overuse and the use of e-liquids that are highly concentrated in nicotine. ${ }^{37}$ In some e-smoking devices, the nicotine boost effect was observed to be greater than with traditional cigarettes due to the rapid inhalation of highly concentrated liquids, which is thought to be one of the major factors with increased dependency. ${ }^{38-40}$ From a larger preventive public health perspective, the issue of nicotine dependency is principally nourished by concerns about e-smoking becoming a springboard for nicotine addiction among youth. Data from the body of literature show high levels of nicotine dependency among adolescents, which is associated with an earlier onset of e-smoking, more frequent daily use, use of highly concentrated nicotine e-liquid, and dual smoking. ${ }^{41,42}$

\section{Prevalence of e-Smoking}

In the present study, experience with and current use of e-cigarettes showed a prevalence of $36.6 \%$ and $11.5 \%$, respectively, in the student population. Subgroup analysis showed that the rate of ever having e-smoked was remarkably higher among ex-smokers $(88.5 \%)$ and current smokers (82.3\%) than among nonsmokers (15.0\%). Additionally, $30.8 \%$ of ex-smokers were current e-smokers, versus $2.7 \%$ of nonsmokers (these results were not presented because they were not within the scope of the study). Although the participants' motivations for e-smoking were not explored in the present study, these differences may suggest the use of e-smoking for smoking cessation purposes. However, use by nonsmokers may be related to unawareness about the fact that e-cigarettes are considered tobacco products. Moreover, previous experience with e-smoking was independently associated with higher rates of favorable attitudes toward the therapeutic use of e-cigarettes, and no significant differences were observed across academic levels. These observations may indirectly reflect the gap of knowledge among the medical students about e-smoking. This can be further supported by social media being the dominant source of knowledge about e-cigarettes, which provide inaccurate information and promote a positive image of e-smoking.

\section{Conclusion}

Approximately one-quarter of the medical students in the present study were likely to be favorably inclined to use e-cigarettes therapeutically as a smoking cessation method or as a risk reduction strategy for patients, and this was highly predicted by previous experience with e-smoking. We noted a substantial gap in knowledge about e-smoking, with low confidence levels and social media being the main source of knowledge. These observations indicate the insufficiency of formal medical education programs regarding the issue, which have resulted in misconceptions about the addictiveness and inadequate awareness of the harmful effects of e-cigarette, leading to non-scientific opinions about its therapeutic use in smoking cessation or as a harm reduction approach. Without excluding a shift in expert opinions, effective awareness campaigns should be implemented among both health professionals and the general population. Such campaigns should promote the majority of experts' attitude regarding the clinical and therapeutic use of e-cigarettes that calls for great caution, stressing the risk of escalated health hazards in the case of normalization due to the intrinsic toxicity of the products or because of inappropriate consumer behaviors.

\section{Abbreviations}

BMI, body mass index; CDC, Centers for Disease Control; CI, confidence interval; EU, European Union; FDA, US Food and Drug Administration; GPA, grade point average; KAU, King Abdulaziz University; OR, odds ratio; SD, standard deviation.

\section{Data Sharing Statement}

All original data is available in the Department of Family Medicine, King Abdulaziz University, Jeddah, Saudi Arabia. 


\section{Ethics Approval and Consent to Participate}

The protocol of the present study was approved by the Research Ethics Committee (REC) of King Abdulaziz University, Jeddah, Saudi Arabia. (Reference No. 22-5696). Written informed consent was obtained and documented from all participants. They were informed about the nature of the study and confidentiality of their response.

\section{Acknowledgments}

The authors are thankful to the medical students of King Abdulaziz University for their participation in this study.

\section{Author Information}

$\mathrm{SH}$ is the director of the health promotion center in King Abdulaziz University, consultant and assistant professor of family medicine. SH is the founder of Dr's for Life volunteer team that focus on raising the awareness about smoking and other factors that affect healthy lifestyle and public health.

\section{Author Contributions}

All authors made a significant contribution to the work reported, whether that is in the conception, study design, execution, acquisition of data, analysis and interpretation, or in all these areas; took part in drafting, revising or critically reviewing the article; gave final approval of the version to be published; have agreed on the journal to which the article has been submitted; and agree to be accountable for all aspects of the work.

\section{Funding}

This work was funded by the Deanship of Scientific Research (DSR), KAU, Jeddah, under grant No. DF-344140-1441. The authors acknowledge DSR with thanks for their technical and financial support. The funders had no role in study design, data collection and analysis, decision to publish, or preparation of the manuscript.

\section{Disclosure}

No disclaimers to declare. No part of the article was presented in any conference proceedings. Dr Sami Alzahrani reports grants from King Abdulaziz University during the conduct of the study. The authors reported no other potential conflicts of interest for this work.

\section{References}

1. Jha P, Peto R. Global effects of smoking, of quitting, and of taxing tobacco. $N$ Engl $J$ Med. 2014;370(1):60-68. doi:10.1056/ NEJMra1308383

2. World Health Organization. Tobacco; 2019. Available from: https:// www.who.int/health-topics/tobacco. Accessed December 26, 2019.

3. World Health Organization. Monitor tobacco use and prevention policies; 2017 Available from: https://www.who.int/tobacco/mpo wer/monitor/en/. Accessed December 26, 2019.

4. Brown J, Beard E, Kotz D, Michie S, West R. Real-world effectiveness of e-cigarettes when used to aid smoking cessation: a crosssectional population study. Addiction. 2014;109(9):1531-1540. doi:10.1111/add.12623

5. Owusu D, Huang J, Weaver SR, et al. Patterns and trends of dual use of e-cigarettes and cigarettes among U.S. adults, 2015-2018. Prev Med Rep. 2019;16:101009. doi:10.1016/j.pmedr.2019.101009

6. Hu SS, Neff L, Agaku IT, et al. Tobacco product use among adults United States, 2013-2014. MMWR Morb Mortal Wkly Rep. 2016;65 (27):685-691. doi:10.15585/mmwr.mm6527a1

7. AlBaik M, Abdrabulnabi AA, Aldahan SM, Alkhadhrawi NH. Electronic cigarette in Saudi Arabia: an online survey. Valley Int J. 2014;1:411-426.

8. Karbouji MA, Abduldaem AM, Allogmani AM, Alharbi AS, Alnozha O, Al-Zalabani AH. Awareness and attitude toward smoking e-cigarettes (vape) among smokers in Saudi Arabia 2017. Egypt $J$ Hosp Med. 2018;70(8).

9. El Dib R, Suzumura EA, Akl EA, et al. Electronic nicotine delivery systems and/or electronic non-nicotine delivery systems for tobacco smoking cessation or reduction: a systematic review and meta-analysis. BMJ Open. 2017;7(2):e012680-e012680. doi:10.1136/bmjopen2016-012680

10. Centers for Disease Control and Prevention. About electronic cigarettes (E-cigarettes); 2019. Available from: https://www.cdc.gov/ tobacco/basic_information/e-cigarettes/about-e-cigarettes.html. Accessed December 26, 2019.

11. Gliem JA, Gliem RR. Calculating, interpreting, and reporting Cronbach's alpha reliability coefficient for Likert-type scales. 2003.

12. Sinniah D, Khoo EJ. E-cigarettes: facts and legal status. IeJSME. 2015;9(3):10-19.

13. Food and Drug Administration. Deeming tobacco products to be subject to the Federal Food, Drug, and Cosmetic Act, as amended by the Family Smoking Prevention and Tobacco Control Act; restrictions on the sale and distribution of tobacco products and required warning statements for tobacco products. Final rule. Fed Regist. 2016;81(90):28973-29106.

14. Kaplan S. FDA delays rules that would have limited e-cigarettes on market. New York Times. 2017; 28.

15. Gottlieb S. The FDA's challenge on e-cigs: minimize the danger to minors while preserving a smoking-cessation tool; 2019. Available from: https://www.wsj.com/articles/the-fdas-challenge-on-e-cigs11561415893. Accessed June 24, 2019.

16. Basham P. Regulating e-Cigarettes \& Heated Tobacco Products: Democratic Lessons for Asia. Washington, DC: Democracy Institute; 2019.

17. McNeill A, Brose LS, Calder R, Bauld L, Robson D. Vaping in England: An Evidence Update February 2019. A Report Commissioned by Public Health England. London: Public Health England; 2019.

18. Goniewicz ML, Knysak J, Gawron M, et al. Levels of selected carcinogens and toxicants in vapour from electronic cigarettes. Tob Control. 2013;23(2):133-139. doi:10.1136/tobaccocontrol-2012050859

19. Shin DW, Kim YI, Kim SJ, et al. Lung cancer specialist physicians' attitudes towards e-cigarettes: a nationwide survey. PLoS One. 2017;12(2):e0172568. doi:10.1371/journal.pone.0172568 
20. Kaisar MA, Prasad S, Liles T, Cucullo L. A decade of e-cigarettes: limited research \& unresolved safety concerns. Toxicology. 2016;365:67-75. doi:10.1016/j.tox.2016.07.020

21. Jensen RP, Luo W, Pankow JF, Strongin RM, Peyton DH. Hidden formaldehyde in e-cigarette aerosols. $N$ Engl J Med. 2015;372 (4):392-394. doi:10.1056/NEJMc1413069

22. Hutzler C, Paschke M, Kruschinski S, Henkler F, Hahn J, Luch A. Chemical hazards present in liquids and vapors of electronic cigarettes. Arch Toxicol. 2014;88(7):1295-1308. doi:10.1007/s00204-0141294-7

23. Stephens WE. Comparing the cancer potencies of emissions from vapourised nicotine products including e-cigarettes with those of tobacco smoke. Tob Control. 2017;27(1):10-17. doi:10.1136/tobaccocontrol-2017-053808

24. Canistro D, Vivarelli F, Cirillo S, et al. E-cigarettes induce toxicological effects that can raise the cancer risk. Sci Rep. 2017;7(1). doi:10.1038/s41598-017-02317-8.

25. Haswell LE, Baxter A, Banerjee A, et al. Reduced biological effect of e-cigarette aerosol compared to cigarette smoke evaluated in vitro using normalized nicotine dose and RNA-seq-based toxicogenomics. Sci Rep. 2017;7(1). doi:10.1038/s41598-017-00852-y.

26. Iskandar AR, Mathis C, Schlage WK, et al. A systems toxicology approach for comparative assessment: biological impact of an aerosol from a candidate modified-risk tobacco product and cigarette smoke on human organotypic bronchial epithelial cultures. Toxicol in Vitro. 2017;39:29-51. doi:10.1016/j.tiv.2016.11.009

27. Breheny D, Oke O, Pant K, Gaça M. Comparative tumor promotion assessment of e-cigarette and cigarettes using the in vitro Bhas 42 cell transformation assay. Environ Mol Mutagen. 2017;58(4):190198. doi:10.1002/em.22091

28. Kalkhoran S, Glantz SA. E-cigarettes and smoking cessation in realworld and clinical settings: a systematic review and meta-analysis. Lancet Respir Med. 2016;4(2):116-128. doi:10.1016/S2213-2600(15) 00521-4

29. Van Gucht D, Baeyens F. Health professionals in Flanders perceive the potential health risks of vaping as lower than those of smoking but do not recommend using e-cigarettes to their smoking patients. Harm Reduct J. 2016;13(1). doi:10.1186/s12954-016-0111-4

30. Ofei-Dodoo S, Kellerman R, Nilsen K, Nutting R, Lewis D. Family physicians' perceptions of electronic cigarettes in tobacco use counseling. J Am Board Fam Med. 2017;30(4):448-459. doi:10.3122/ jabfm.2017.04.170084

31. Cummins S, Leischow S, Bailey L, et al. Knowledge and beliefs about electronic cigarettes among quitline cessation staff. Addict Behav. 2016;60:78-83. doi:10.1016/j.addbeh.2016.03.031
32. Farrimond H, Abraham C. Developing E-cigarette friendly smoking cessation services in England: staff perspectives. Harm Reduct J. 2018;15(1). doi:10.1186/s12954-018-0244-8

33. Kollath-Cattano C, Thrasher JF, Osman A, Andrews JO, Strayer SM. Physician advice for e-cigarette use. J Am Board Fam Med. 2016;29 (6):741-747. doi:10.3122/jabfm.2016.06.160092

34. Singh B, Hrywna M, Wackowski OA, Delnevo CD, Jane lewis M, Steinberg MB. Knowledge, recommendation, and beliefs of e-cigarettes among physicians involved in tobacco cessation: a qualitative study. Prev Med Rep. 2017;8:25-29. doi:10.1016/j. pmedr.2017.07.012

35. Egnot E, Jordan K, Elliott JO. Associations with resident physicians' early adoption of electronic cigarettes for smoking cessation. Postgrad Med J. 2016;93(1100):319-325. doi:10.1136/postgradmedj-2016-134058

36. Russell C, Dickson T, McKeganey N. Advice from former-smoking e-cigarette users to current smokers on how to use e-cigarettes as part of an attempt to quit smoking. Nicotine Tobacco Res. 2017;20 (8):977-984. doi:10.1093/ntr/ntx176

37. Jankowski M, Krzystanek M, Zejda JE, et al. E-cigarettes are more addictive than traditional cigarettes - a study in highly educated young people. Int J Environ Res Public Health. 2019;16(13):2279. doi:10.3390/ijerph16132279

38. Ramôa CP, Hiler MM, Spindle TR, et al. Electronic cigarette nicotine delivery can exceed that of combustible cigarettes: a preliminary report. Tob Control. 2015;25(e1):e6-e9. doi:10.1136/tobaccocontrol2015-052447

39. Hajek P, Przulj D, Phillips A, Anderson R, McRobbie H. Nicotine delivery to users from cigarettes and from different types of e-cigarettes. Psychopharmacology. 2017;234(5):773-779. doi:10.1007/ s00213-016-4512-6

40. St.Helen G, Havel C, Dempsey DA, Jacob P, Benowitz NL. Nicotine delivery, retention and pharmacokinetics from various electronic cigarettes. Addiction. 2015;111(3):535-544. doi:10.1111/add.13183

41. Morean ME, Krishnan-Sarin S, O’Malley SS. Assessing nicotine dependence in adolescent e-cigarette users: the 4-item PatientReported Outcomes Measurement Information System (PROMIS) nicotine dependence item bank for electronic cigarettes. Drug Alcohol Depend. 2018;188:60-63. doi:10.1016/j. drugalcdep.2018.03.029

42. Case KR, Mantey DS, Creamer MR, Harrell MB, Kelder SH, Perry CL. E-cigarette- specific symptoms of nicotine dependence among Texas adolescents. Addict Behav. 2018;84:57-61. doi:10.1016/j. addbeh.2018.03.032
Risk Management and Healthcare Policy

\section{Publish your work in this journal}

Risk Management and Healthcare Policy is an international, peerreviewed, open access journal focusing on all aspects of public health, policy, and preventative measures to promote good health and improve morbidity and mortality in the population. The journal welcomes submitted papers covering original research, basic science, clinical \& epidemiological studies, reviews and evaluations, guidelines, expert opinion and commentary, case reports and extended reports. The manuscript management system is completely online and includes a very quick and fair peer-review system, which is all easy to use. Visit http://www.dovepress.com/testimonials.php to read real quotes from published authors. 